abnormality that is associated with unexplained infertility and which is not due to low concentrations of circulating progesterone.

This work was funded by a grant from Birthright.

1 Templeton AA, Penney GC. The incidence, characteristics, and prognosis of patients whose infertility is unexplained. Fertil Steril 1982;37:175-82.

2 Aplin JD, Seif MW. A monoclonal antibody to a cell surface determinant in human endometrial epithelium: stage-specific expression in the menstrua cycle. Am f Obstet Gynecol 1987;156:250-3.

3 Seif $\mathrm{MW}$, Aplin JD, Foden LJ, Tindall VR. A novel approach for monitoring the endometrial cycle and detecting ovulation. Am $\mathcal{F}$ Obstet Gynecol 1989;160:357-62

4 Smith RA, Seif MW, Rogers AW, et al. The endometrial cycle: the expression of a secretory component correlated with the luteinising hormone peak. Hum Reprod 1989:4:236-42.

5 Aplin JD, Hoadley ME, Seif MW. Hormonally regulated secretion of keratan sulphate by human endometrial epithelium. Biochem Soc Trans 1989;17. 136-7.

6 Hoadley ME, Aplin JD, Seif MW. Menstrual cycle-dependent expression of keratan sulphate in human endometrium. Biochem 7 1990;266:757-63.
7 Seif $\mathrm{MW}$, Aplin JD, Buckley CH. Luteal phase defect: the possibility of an immunohistochemical diagnosis. Fertil Steril 1989;51:273-9.

8 Seif $\mathrm{MW}$, Aplin JD, Awad H, Wells D. The effect of the intrauterine contraceptive device on endometrial secretory function: a possible mode of action. Contraception 1989;40:81-9.

9 Dockery P, Li TC, Rogers AW, Cooke ID, Lenton EA, Warren MA. An examination of the variation in timed endometrial biopsies. Hum Reprod 1988:3:715-20.

10 Li TC, Rogers AW, Lenton EA, Dockery P, Cooke ID. A comparison between two methods of chronological dating of human endometrial biopsies during the luteal phase, and their correlation with histologic dating. Fertil Steril 1987;48:928-32.

11 Belsey MA, Eliasson R, Gallegos AJ, Moghissi KS, Paulsen CA, Prased MRN Laboratory manual for the examination of semen andemen-cervical mucus interaction. Singapore: Press Concern, 1980

12 Lenton EA, Gelsthorpe CH, Harper R. Measurement of progesterone in saliva: assessment of the normal, fertile range using spontaneous conception cycles. Clin Endocrinol 1988;28:637-46.

13 Rogers AW. The microscopy and photography of autoradiographs. In Rogers $\mathrm{AW}$, ed. Techniques of autoradiography. 3rd ed. Amsterdam: Elsevier, 1979:148-64

14 Li TC, Lenton EA, Dockery P, Rogers AW, Cooke ID. The relation between daily salivary progesterone profile and endometrial development in the luteal phase of fertile and infertile women. Br F Obstet Gynaecol 1989;96:445-53.

(Accepted 30 March 1990)

\title{
Low back pain of mechanical origin: randomised comparison of chiropractic and hospital outpatient treatment
}

\author{
T W Meade, Sandra Dyer, Wendy Browne, Joy Townsend, A O Frank
}

\section{Abstract}

Objective-To compare chiropractic and hospital outpatient treatment for managing low back pain of mechanical origin.

Design-Randomised controlled trial. Allocation to chiropractic or hospital management by minimisation to establish groups for analysis of results according to initial referral clinic, length of current episode, history, and severity of back pain. Patients were followed up for up to two years.

Setting-Chiropractic and hospital outpatient clinics in 11 centres.

Patients-741 Patients aged 18-65 who had no contraindications to manipulation and who had not been treated within the past month.

Interventions - Treatment at the discretion of the chiropractors, who used chiropractic manipulation in most patients, or of the hospital staff, who most commonly used Maitland mobilisation or manipulation, or both.

Main outcome measures-Changes in the score on the Oswestry pain disability questionnaire and in the results of tests of straight leg raising and lumbar flexion.

Results-Chiropractic treatment was more effective than hospital outpatient management, mainly for patients with chronic or severe back pain. A benefit of about $7 \%$ points on the Oswestry scale was seen at two years. The benefit of chiropractic treatment became more evident throughout the follow up period. Secondary outcome measures also showed that chiropractic was more beneficial.

Conclusions - For patients with low back pain in whom manipulation is not contraindicated chiropractic almost certainly confers worthwhile, long term benefit in comparison with hospital outpatient management. The benefit is seen mainly in those with chronic or severe pain. Introducing chiropractic into NHS practice should be considered.

\section{Introduction}

The high incidence of back pain, its chronic and recurrent nature in many patients, and its contribution as a main cause of absence from work are well known. No general consensus exists about the most effective treatment. Largely anecdotally, patients and therapists often claim great improvements after manipulative treatment by alternative practitioners, including chiropractors. A recent report from the board of science and education of the BMA considered that manipulative treatment of back pain by lay practitioners may provide "a safe and helpful service," thus strengthening the Cochrane committee's recommendation that randomised trials of treatment for back pain should include an evaluation of heterodox methods.

A comparison of chiropractic with conventional hospital outpatient management of low back pain could take one of two main forms. Firstly, it could be a "pragmatic" trial, which would test what happens in day to day practice and in which details of the type, frequency, and duration of treatment would be at the discretion of the chiropractor or hospital team. ${ }^{3}$ The disadvantage of a pragmatic trial is that if a clear difference is found between the treatments it may not be possible to identify the components of the more successful treatment that were responsible. Secondly, it could be a "fastidious" trial, which would compare chiropractic manipulation with a particular form of non-manipulative physiotherapy. ${ }^{3}$ Though this type of trial may be more likely to identify specific components of treatment that are effective, there would be a high chance of not including the effective components because of the many techniques used to treat back pain. ${ }^{4}$ In addition, its results might have only limited applicability.

We adopted a pragmatic approach for two main reasons: firstly, because of the probable difficulty of securing agreement about standard forms of treatment, particularly in hospital, and consequently the smal number of patients who could be recruited into a fastidious trial and, secondly, because the effectiveness of treatment in day to day practice, whether chiropractic or in hospital, is of most immediate interest to patients as well as doctors and therapists.

\section{Patients and methods}

CENTRES AND CLINICS

The study was based on the methods of a feasibility study. ${ }^{5}$ Each centre consisted of a chiropractic clinic 
and a hospital clinic. After the feasibility study had been completed 11 centres with hospital and chiropractic clinics within a reasonable distance of one another agreed to take part in this trial.

TABLE I-Reasons for ineligibility for or exclusion from trial in patients with back pain presenting to hospital or chiropractor in two centres. Figures are numbers (percentages)

\begin{tabular}{lcc}
\hline & \multicolumn{2}{c}{ Initially attended: } \\
\cline { 2 - 3 } & Hospital $(\mathrm{n}=751)$ & Chiropractor $(\mathrm{n}=543)$ \\
\hline Ineligibility: & & \\
Outside age range & $67(9)$ & $17(3)$ \\
Nerve root affected & $168(22)$ & $124(23)$ \\
Spinal abnormality & $22(3)$ & $24(4)$ \\
Recent treatment & $53(7)$ & $52(10)$ \\
Free of pain & $99(13)$ & $6(1)$ \\
Other* & $207(28)$ & $81(15)$ \\
\hline Total & $616(82)$ & $304(56)$ \\
\hline Exclusion: & & $62(11)$ \\
Unwilling, no time & $16(2)$ & $87(16)$ \\
Wanted chiropractic treatment & $9(1)$ & $23(4) \dagger$ \\
Wanted hospital treatment & $2(0 \cdot 3)$ & $172(32)$ \\
Other & $27(4)$ & \\
\hline Total & & \\
\hline
\end{tabular}

*Includes other diseases, psychosocial difficulties, previous surgery, and litigation pending.

†Includes previously unsuccessful treatment in hospital.

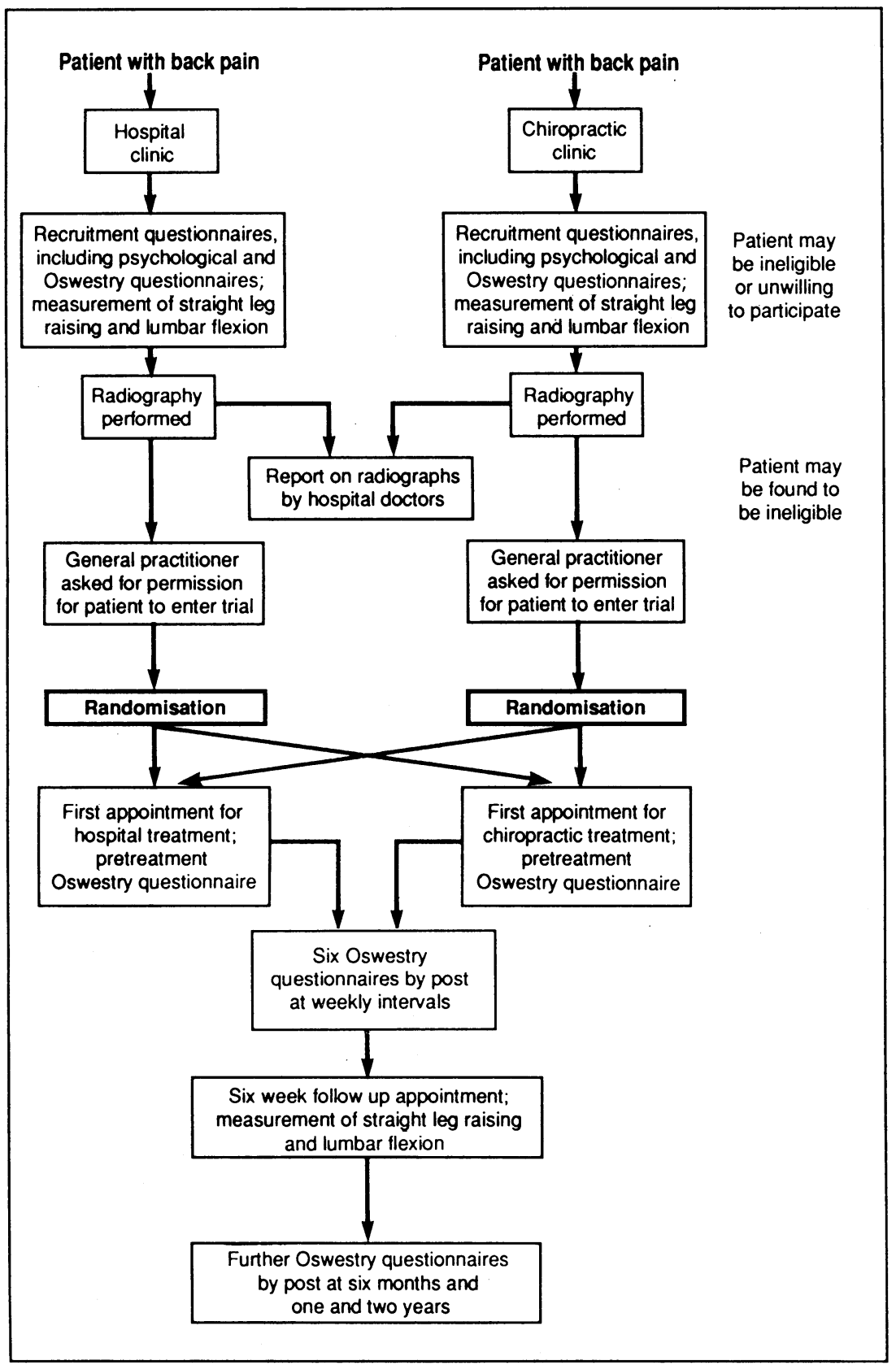

FIG 1 -Recruitment and follow up procedures
PATIENTS

The main criterion for eligibility was that patients should have no contraindication to manipulation as almost all the patients treated by chiropractic would receive manipulation and it was important to avoid damage by manipulation. Thus patients were excluded if there was evidence that a nerve root was affected, though restricted straight leg raising on its own was not a reason for exclusion; major structural abnormalities were visible on radiography; or osteopenia or an infectious cause was suspected and for various other reasons, including social conditions and pending litigation. Only patients aged 18 to 65 who had not been treated within the past month and who had not attended the same referral clinic within the past two years were recruited.

Two of the 11 centres kept a record of all patients presenting with back pain. Table I summarises the reasons for ineligibility or exclusion in these two centres, confirming the general finding of the feasibility study in one of the other centres that contraindications were commoner among patients presenting initially to hospital while considerations of convenience-for example, to avoid waiting and delay in starting treatment-were commoner among patients initially presenting to the chiropractors. Among 135 eligible patients referred to hospital $108(80 \%)$ entered the trial, compared with 67 of $239(28 \%)$ referred to chiropractors. In all, $175(47 \%)$ of those eligible in these two centres entered. Figure 1 summarises the recruitment, investigation, treatment, and follow up procedures in eligible patients.

All patients underwent radiography of the lumbar spine, the $x$ ray films (whether taken by the chiropractor or in hospital) being reported on by a hospital radiologist. Permission was then sought from general practitioners for each patient's participation in order to comply with the General Medical Council's advisory guidelines about collaboration with heterodox practitioners. Two general practitioners in one centre said that they did not want any of their patients included. Permission was also withheld for five patients under other general practitioners. The General Medical Council also advised that the medically qualified members of the hospital teams should satisfy themselves about the competence of the chiropractors. This was done through discussions during the early stages of the trial.

The purpose of the trial was explained to eligible patients by the nurse coordinator in each centre, who pointed out that participation would mean an equal chance of being treated by chiropractic or conventional hospital methods, the decision being made at random. Patients were also given a written explanation and told that if they were allocated for treatment at the clinic they had not originally attended they would be free at any stage to return to the original clinic. All patients signed a consent form, and the study was approved by the ethical committees of the 11 centres.

The fees of patients receiving chiropractic treatment were paid by grants from funding agencies regardless of whether these patients had originally attended chiropractic or hospital clinics. The number of patients recruited in each centre ranged from 14 to 198.

General practitioners in three centres had direct access to physiotherapy departments for all or part of the trial, accounting for the higher proportion of patients with short episodes of pain compared with that in the feasibility study.

OUTCOME

The patients' progress was measured with the Oswestry back pain questionnaire, ${ }^{6}$ which gives scores for 10 sections - for example, intensity of pain, difficulty with lifting, walking, and travelling. The result is 
expressed on a scale ranging from $0 \%$ (no pain or difficulties) to $100 \%$ (highest score for pain or difficulty on all items). Each patient completed the questionnaire at recruitment and shortly before starting treatment. Further questionnaires were then sent by post with prepaid reply envelopes at weekly intervals for six weeks, at six months, and at one and two years after entry. Subsidiary measures of outcome included assessing straight leg raising with a goniometer and lumbar flexion ${ }^{8}$; both were measured at entry and at six weeks by the coordinating nurse, the readings made at entry being unavailable to her at the six week follow up appointment. The results reported here include the responses to follow up questionnaires and other measures completed by the end of September 1989, when all patients had been followed up for six months, fewer patients having completed one and two year follow up questionnaires.

At entry patients also completed psychological questionnaires dealing with depressive symptoms, somatic awareness, and inappropriate symptoms. ${ }^{9}$

\section{TREATMENT}

Each patient's treatment was at the discretion of the chiropractor or hospital team. Based on the pattern of chiropractic treatments in the feasibility study and in discussion with a representative of the British Chiropractic Association the chiropractors were allowed to give a maximum of 10 treatments, which were intended to be concentrated within the first three months but could be spread over a year if considered necessary.

\section{STATISTICS}

We recruited as many patients as the available funding allowed. We estimated from the feasibility study that about 2000 patients would be needed to detect a difference between the two approaches of $2 \%$ points on the Oswestry scale (at the 5\% level, with $90 \%$ power)-for example, a decrease in Oswestry score from $30 \%$ to $25 \%$ in one group compared with a decrease from $30 \%$ to $23 \%$ in the other-and that differences of $2 \cdot 5 \%, 3.0 \%, 4 \cdot 0 \%$ and $5.0 \%$ points would require about $1200,850,500$, and 300 patients respectively. Table II gives examples of the implications of a range of differences in mean Oswestry scores.

Patients were randomly allocated to treatment, and the method of minimisation ${ }^{10}$ was used within each centre to establish groups for analysis of results according to initial referral clinic, length of current episode (more or less than a month), presence or

TABLE II-Examples of interpretation of differences or changes in Oswestry scores

\begin{tabular}{l|l}
\hline & $\begin{array}{c}\text { Difference \% } \\
\text { points }\end{array}$ \\
\hline $\begin{array}{l}\text { No pain compared with mild pain; or } \\
\text { Moderate pain compared with fairly severe pain; or } \\
\text { Able to lift only light weights compared with not able to } \\
\text { lift anything; or }\end{array}$ & $2 \%$ \\
$\begin{array}{l}\text { Able to sit for one hour compared with only half an hour } \\
\text { No pain compared with moderate pain; or }\end{array}$ \\
$\begin{array}{l}\text { Moderate pain compared with very severe pain; or } \\
\text { Able to lift light to medium weights compared with unable } \\
\text { to lift anything; or }\end{array}$ \\
$\begin{array}{l}\text { Able to sit for up to one hour compared with less } \\
\text { than lo minutes }\end{array}$ \\
$\begin{array}{l}\text { Mild pain, ability to lift heavy weights without extra pain, } \\
\text { and ability to sit for up to one hour compared with } \\
\text { moderate pain, ability to lift heavy weights only if } \\
\text { conveniently positioned, and unable to sit for more than } \\
\text { half an hour }\end{array}$ \\
$\begin{array}{l}\text { Mild pain, ability to lift light to medium weights, and } \\
\text { ability to sit for up to one hour compared with fairly severe } \\
\text { pain, unable to lift anything, and able to sit for up to half } \\
\text { an hour }\end{array}$
\end{tabular}

* Scores for sections on lifting, sitting, and pain intensity account for most of the total Oswestry scores. The examples assume no differences in other items. absence of a history of back pain, and an Oswestry score at entry of $>40 \%$ or $\leqslant 40 \%$. The feasibility study had shown that the length of the current episode, in particular, clearly distinguished two groups of patients, those with a short current episode improving much more rapidly (regardless of treatment) than those with longer episodes. ${ }^{5}$

The interval between recruitment and the start of treatment varied slightly among the four referral and treatment clinic groups. To allow for any changes before the start of treatment the results were based on changes in Oswestry scores, and this also allowed for the small differences in pretreatment scores between the hospital and chiropractic groups (see table III).

TABLE III - Characteristics of patients according to randomised treatment group. Figures are numbers (percentages) unless otherwise stated

\begin{tabular}{|c|c|c|}
\hline & $\begin{array}{l}\text { Hospital group } \\
\quad(n=357)\end{array}$ & $\begin{array}{l}\text { Chiropractic } \\
\text { group }(n=384)\end{array}$ \\
\hline Mean (SD) age (years) & $38 \cdot 5(10 \cdot 8)$ & $38.9(11 \cdot 2)$ \\
\hline Men & $190(53)$ & $190(49)$ \\
\hline Women & $167(47)$ & $194(51)$ \\
\hline \multicolumn{3}{|l|}{ Social class ${ }^{\star}$ : } \\
\hline I and II & $113(34)$ & $123(34)$ \\
\hline III & $163(49)$ & $180(50)$ \\
\hline IV and V & $52(16)$ & $50(14)$ \\
\hline Armed forces & $6(2)$ & $7(2)$ \\
\hline Self employed & $47(13)$ & $42(11)$ \\
\hline \multicolumn{3}{|l|}{ Initially attended: } \\
\hline Hospital clinic & $194(54)$ & $189(49)$ \\
\hline Chiropractic clinic & $163(46)$ & $195(51)$ \\
\hline \multicolumn{3}{|l|}{ Back pain: } \\
\hline With history & $271(76)$ & $288(75)$ \\
\hline With current episode $>1$ month & $214(60)$ & $226(59)$ \\
\hline With Oswestry score $>40 \%$ & $70(20)$ & $78(20)$ \\
\hline Previously treated (any method) & $296(83)$ & $326(85)$ \\
\hline Previously using drugs $†$ & $192(54)$ & $212(55)$ \\
\hline $\begin{array}{l}\text { Mean Oswestry score at recruitment } \\
\text { (SD) }\end{array}$ & $30 \cdot 1(13 \cdot 8)$ & $30 \cdot 6(13 \cdot 7)$ \\
\hline $\begin{array}{l}\text { Mean pretreatment Oswestry score } \\
\text { (SD) }\end{array}$ & $28 \cdot 5(14 \cdot 1)$ & $29 \cdot 8(14 \cdot 2)$ \\
\hline
\end{tabular}

^Details not known in 47 patients.

† Mainly analgesics and anti-inflammatory drugs.

The negative sign for changes in Oswestry scores in figures 2 and 3 means a fall - that is an improvement in these scores (between pretreatment and follow up) reflecting the well known tendency for back pain to improve spontaneously as well as any treatment effects. (Similar figures for results according to referral clinic, length of current episode, and past history are available on request.)

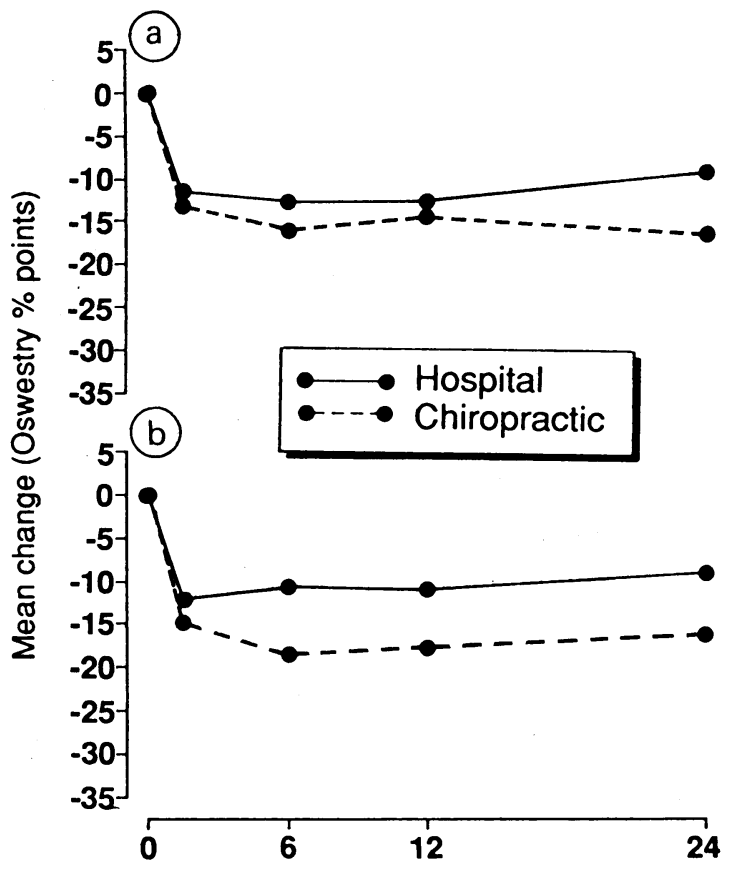

Time since start of treatment (months)

FIG 2-Mean changes in Oswestry scores: $a=$ for all patients, $b=$ for all patients who had been followed up for two years 


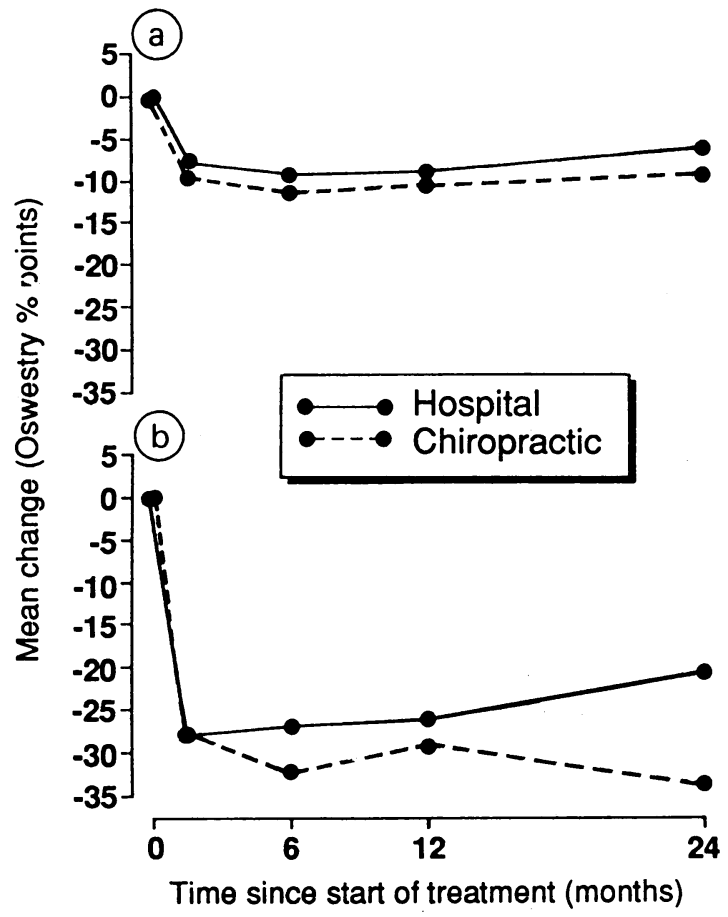

FIG 3-Mean changes in Oswestry score: $a=$ for all patients with recruitment score $\leqslant 40 \%$ points, $b=$ for all patients with recruitment score $>40 \%$ points

The results were analysed by intention to treat (subject to availability of data on follow up and at entry for individual patients). Differences between the mean changes in the two groups were tested by unpaired $t$ tests. $\chi^{2}$ Tests were used to detect any significant differences between the two treatment groups-for example, in the proportion of patients off work. Missing data account for slightly differing numbers in the text and tables.

\section{Results}

Patients were recruited during March 1986 to March 1989. In all, 781 patients were recruited from the 11 participating centres. Of these, 24 ( 13 from hospitals, and 11 from chiropractic clinics) were later found to be ineligible and 16 (eight, eight) withdrew from the study almost immediately so that 741 started treatment (384 receiving chiropractic and 357 hospital treatment). Table III summarises the characteristics of the patients in the two treatment groups.

Follow up Oswestry questionnaires were returned by $90 \%$ patients at six weeks, by $84 \%$ at six months ( $86 \%$ treated by chiropractors, $81 \%$ in hospital), by $79 \%$ at a year ( $83 \%$ chiropractors, $74 \%$ hospital) and by $72 \%$ at two years (76\% chiropractors, $69 \%$ hospital). Because non-response was more common among patients treated in hospital than by chiropractors and randomisation had by chance resulted in a few more patients being allocated to chiropractors (see above) there were usually more patients treated by chiropractors than in hospitals in the analyses. There were no obvious systematic differences in the characteristics of non-responders treated by chiropractors or in hospital.

Table IV summarises the treatments received in the chiropractic and hospital clinics. Not all hospitals had access to hydrotherapy, but otherwise there were no appreciable differences in treatment patterns among hospitals. Virtually all the patients treated by chiropractors received chiropractic manipulation such as high velocity, low amplitude manipulation at some stage. Patients treated by chiropractors received about $44 \%$ more treatments than those treated in hospital. At six weeks $79 \%$ of hospital patients had completed treatment compared with $29 \%$ of patients treated by chiropractic. Almost all patients had completed treatment by 12 weeks in the hospital group and by 30 weeks in the chiropractic group (97\%). The chiropractors generally treated all patients over a similar period whereas the hospital therapists treated patients with long episodes of back pain who were never free of symptoms for longer periods than those with short episodes.

Of the 741 patients who started treatment, 29 changed their treatment centre ( 22 within the first six weeks). Sixty patients did not complete their course of treatment and 77 did not attend for six week follow up with the nurse coordinator. Altogether 608 completed the trial to six weeks without missing any treatments or the six week questionnaire, changing treatment centre, or missing follow up appointments.

Table $\mathrm{V}$ gives the differences in the changes in Oswestry scores between the two treatment groups. Figure 2a, which is based on all data for all patients, shows that the change for those treated by chiropractic was consistently greater than that for those treated in hospital. At two years the patients treated by chiropractic had improved by $7 \%$ more than those treated in hospital $(p=0 \cdot 01)$. When the analysis was confined to patients all of whom had been followed up for two years and who had complete data at six weeks, six months, one year, and two years the general pattern was similar (fig $2 \mathrm{~b}$ ) but the differences at six months and a year were greater. Among patients who originally attended hospital there was no difference between chiropractic and hospital treatment until two years after entry, when the patients treated by the chiropractors had improved more than those treated in hospital (table V). For patients who originally attended a chiropractor the chiropractic treatment was more effective throughout the follow up period. When the results were confined to patients with complete follow up data for two years, however, the patients in both referral groups who were treated by chiropractic tended to show greater improvement throughout the follow up.

The results were also analysed according to length of the current episode of pain. In both groups those treated by chiropractors improved more than those treated in hospital, the benefit possibly being seen somewhat earlier in those with a long current episode (table V). There was no difference between the two treatments in those with no history of back pain, but chiropractic treatment was more effective than hospital treatment in those with a history. Figure 3 shows that those with Oswestry scores $>40 \%$ at entry responded better to chiropractic treatment (by $13 \%$ at two years) than those with scores $\leqslant 40 \%$.

Between follow up at one and two years $17 \%(18 / 107)$ of those initially treated by chiropractors had further chiropractic treatment and $24 \%$ (22/92) of those initially treated in hospital had further hospital treatment.

TABLE IV-Numbers (percentages) of patients receiving specified treatments ${ }^{\star}$ and mean numbers of treatment sessions

\begin{tabular}{|c|c|c|}
\hline & $\begin{array}{c}\text { Treated in } \\
\text { hospital }(n=339)\end{array}$ & $\begin{array}{c}\text { Treated by } \\
\text { chiropractor } \\
(\mathbf{n}=378)\end{array}$ \\
\hline Maitland mobilisation or manipulation, & $243(72)$ & $6(2)$ \\
\hline Cyriax manipulation & $42(12)$ & \\
\hline Chiropractic manipulation & & $375(99)$ \\
\hline Traction & $86(25)$ & $8(2)$ \\
\hline Corset & $13(4)$ & $8(2)$ \\
\hline Exercises & $102(30)$ & $33(9)$ \\
\hline \multicolumn{3}{|l|}{ No (SD) of treatment visits: } \\
\hline In six weekst & $5 \cdot 6(3 \cdot 7)$ & $6 \cdot 9(2 \cdot 1)$ \\
\hline Total $\dagger$ & $6 \cdot 3(4 \cdot 8)$ & $9 \cdot 1(3 \cdot 6)$ \\
\hline
\end{tabular}

* Many patients, especially those treated in hospital, received more than one type of treatment. Data on 24 patients were incomplete. Other treatments not shown above included short wave diathermy and hydrotherapy. tp $<0.0001$. 
TABLE IV-Differences (95\% confidence intervals) in changes in Oswestry score (mean score hospital group minus mean score for chiropractic group $)$

\begin{tabular}{|c|c|c|c|c|}
\hline & Six weeks & Six months & One year & Two years \\
\hline All patients & $\begin{array}{c}1 \cdot 69(-0.74 \text { to } 4 \cdot 12) \\
H=309, C=357\end{array}$ & $\begin{array}{c}3 \cdot 31^{\star}(0 \cdot 51 \text { to } 6 \cdot 11) \\
H=282, C=325\end{array}$ & $\begin{array}{c}2 \cdot 09(-1 \cdot 13 \text { to } 5 \cdot 31) \\
\mathrm{H}=207, \mathrm{C}=247\end{array}$ & $\begin{array}{c}7 \cdot 16^{\star \star}(1 \cdot 86 \text { to } 12 \cdot 45) \\
H=90, C=104\end{array}$ \\
\hline All patients with results at two years & $\begin{array}{c}2 \cdot 92(-2 \cdot 27 \text { to } 8 \cdot 11) \\
\mathrm{H}=83, \mathrm{C}=97\end{array}$ & $\begin{array}{c}7 \cdot 89^{\star \star}(2 \cdot 35 \text { to } 13 \cdot 42) \\
\mathrm{H}=83, \mathrm{C}=97\end{array}$ & $\begin{array}{c}6 \cdot 59^{\star \star}(1.79 \text { to } 11 \cdot 40) \\
\mathrm{H}=83, \mathrm{C}=97\end{array}$ & $\begin{array}{c}7 \cdot 45^{\star \star}(2 \cdot 08 \text { to } 12 \cdot 82) \\
\mathrm{H}=83, \mathrm{C}=97\end{array}$ \\
\hline \multicolumn{5}{|c|}{ An } \\
\hline All results & $\begin{array}{c}-0 \cdot 25(-3 \cdot 68 \text { to } 3 \cdot 19) \\
\mathrm{H}=172, \mathrm{C}=168\end{array}$ & $\begin{array}{c}-0.32(-4.41 \text { to } 3 \cdot 78) \\
H=149, C=154\end{array}$ & $\begin{array}{c}-0.94(-5.88 \text { to } 3.99) \\
H=110, C=110\end{array}$ & $\begin{array}{c}5 \cdot 74(-1 \cdot 12 \text { to } 12 \cdot 61) \\
\mathrm{H}=56, \mathrm{C}=54\end{array}$ \\
\hline With results at two years & $\begin{array}{c}-0.49(-6.97 \text { to } 5.99) \\
H=52, C=51\end{array}$ & $\begin{array}{c}3.95(-3.04 \text { to } 10.93) \\
\mathrm{H}=52, \mathrm{C}=51\end{array}$ & $\begin{array}{c}4.84(-1.69 \text { to } 11 \cdot 37) \\
H=52, C=51\end{array}$ & $\begin{array}{c}5.98(-1.08 \text { to } 13.05) \\
\mathrm{H}=52, \mathrm{C}=51\end{array}$ \\
\hline \multicolumn{5}{|l|}{ Chiropractic referrals: } \\
\hline All results & $\begin{array}{c}3.37^{\star}(0.01 \text { to } 6.73) \\
H=137, C=189\end{array}$ & $\begin{array}{c}6.75^{\star \star \star}(2.92 \text { to } 10.58) \\
H=133, C=171\end{array}$ & $\begin{array}{c}4 \cdot 87^{\star \star}(0 \cdot 80 \text { to } 8 \cdot 94) \\
\mathrm{H}=97, \mathrm{C}=137\end{array}$ & $\begin{array}{c}7 \cdot 82(-0.62 \text { to } 16 \cdot 27) \\
H=34, C=50\end{array}$ \\
\hline With results at two years & $\begin{array}{c}6.49(-1.94 \text { to } 14.92) \\
H=31, C=46\end{array}$ & $\begin{array}{c}12 \cdot 35^{\star \star}(2 \cdot 75 \text { to } 21 \cdot 94) \\
H=31, C=46\end{array}$ & $\begin{array}{c}8 \cdot 17^{\star}(0 \cdot 85 \text { to } 15 \cdot 48) \\
\mathrm{H}=31, \mathrm{C}=46\end{array}$ & $\begin{array}{c}8 \cdot 71^{\star}(0 \cdot 15 \text { to } 17 \cdot 27) \\
H=31, C=46\end{array}$ \\
\hline $\begin{array}{l}\text { Duration of current episode: } \\
\quad \leqslant 1 \text { month }\end{array}$ & $\begin{array}{c}0.09(-3.98 \text { to } 4.15) \\
H=126, C=150\end{array}$ & $\begin{array}{c}4.32(-0.31 \text { to } 8.95) \\
H=116, C=138\end{array}$ & $\begin{array}{c}2 \cdot 21(-3 \cdot 06 \text { to } 7 \cdot 48) \\
H=86, C=97\end{array}$ & $\begin{array}{c}9 \cdot 32^{\star}(0.07 \text { to } 18 \cdot 56) \\
\mathrm{H}=39, \mathrm{C}=40\end{array}$ \\
\hline$>1$ month & $\begin{array}{c}2 \cdot 61(-0 \cdot 10 \text { to } 5 \cdot 33) \\
\mathrm{H}=183, \mathrm{C}=207\end{array}$ & $\begin{array}{c}2.35(-0.86 \text { to } 5.56) \\
H=166, C=187\end{array}$ & $\begin{array}{c}2 \cdot 39(-1 \cdot 41 \text { to } 6 \cdot 19) \\
H=121, C=150\end{array}$ & $\begin{array}{c}6.60^{\star}(0.76 \text { to } 12 \cdot 44) \\
H=51, C=64\end{array}$ \\
\hline \multicolumn{5}{|c|}{$\mathrm{H}=183, \mathrm{C}=2 \mathrm{~V} /$} \\
\hline Yes & $\begin{array}{c}2 \cdot 04(-0 \cdot 80 \text { to } 4 \cdot 88) \\
H=242, C=270\end{array}$ & $\begin{array}{c}3 \cdot 11(-0 \cdot 15 \text { to } 6 \cdot 37) \\
H=220, C=245\end{array}$ & $\begin{array}{c}2.99(-0.83 \text { to } 6.80) \\
H=162, \mathrm{C}=184\end{array}$ & $\begin{array}{c}8 \cdot 31^{\star \star}(2 \cdot 24 \text { to } 14 \cdot 38) \\
H=75, C=73\end{array}$ \\
\hline No & $\begin{array}{c}0.51(-4 \cdot 13 \text { to } 5 \cdot 14) \\
H=67, C=87\end{array}$ & $\begin{array}{c}4.04(-1.37 \text { to } 9 \cdot 46) \\
H=62, C=80\end{array}$ & $\begin{array}{c}-0.99(-6.88 \text { to } 4.91) \\
H=45, C=63\end{array}$ & $\begin{array}{c}1.42(-10 \cdot 12 \text { to } 12.95) \\
\mathrm{H}=15, \mathrm{C}=31\end{array}$ \\
\hline \multicolumn{5}{|l|}{ Oswestry score at entry: } \\
\hline$<40 \%$ & $\begin{array}{c}1 \cdot 73(-0.28 \text { to } 3 \cdot 74) \\
H=251, C=284\end{array}$ & $\begin{array}{c}2 \cdot 39^{\star}(0 \cdot 05 \text { to } 4 \cdot 73) \\
H=226, C=256\end{array}$ & $\begin{array}{c}1.76(-1 \cdot 13 \text { to } 4 \cdot 65) \\
H=163, C=194\end{array}$ & $\begin{array}{c}3 \cdot 19(-1 \cdot 52 \text { to } 7 \cdot 90) \\
H=71, C=74\end{array}$ \\
\hline$>40 \%$ & $\begin{array}{c}-0 \cdot 14(-7 \cdot 35 \text { to } 7 \cdot 07) \\
H=58, C=73\end{array}$ & $\begin{array}{c}5.59(-2.79 \text { to } 13 \cdot 97) \\
\mathrm{H}=56, \mathrm{C}=69\end{array}$ & $\begin{array}{c}3 \cdot 15(-5 \cdot 57 \text { to } 11 \cdot 86) \\
\mathrm{H}=44, \mathrm{C}=53\end{array}$ & $\begin{array}{c}13 \cdot 13^{\star}(0 \cdot 24 \text { to } 26 \cdot 01) \\
H=19, C=30\end{array}$ \\
\hline
\end{tabular}

${ }^{\star} p \leqslant 0 \cdot 05,{ }^{\star \star} p \leqslant 0 \cdot 01,{ }^{\star \star \star} p \leqslant 0 \cdot 001$

$\dagger \mathrm{H}=$ Number of patients in hospital group. $\mathrm{C}=$ number of patients in chiropractic group.

TABLE VI - Mean change at six weeks (number of patients) for straight leg raising and lumbar flexion, and percentages of patients recording other events according to treatment group

\begin{tabular}{|c|c|c|c|}
\hline & $\begin{array}{l}\text { Treated in } \\
\text { hospital }\end{array}$ & $\begin{array}{l}\text { Treated by } \\
\text { chiropractor }\end{array}$ & $\begin{array}{l}\text { Difference between two groups } \\
\text { (95\% confidence interval) }\end{array}$ \\
\hline \multicolumn{4}{|l|}{ Straight leg raising $\left(^{\circ}\right)$ : } \\
\hline Right leg & $5 \cdot 0(291)$ & $7 \cdot 1(325)$ & $2 \cdot 1(0 \cdot 0 \text { to } 4 \cdot 1)^{\star}$ \\
\hline Left leg & $5 \cdot 3(288)$ & $5 \cdot 8(323)$ & $0.5(-1.6$ to 2.6$)$ \\
\hline Lumbar flexion $(\mathrm{cm})$ & $0.62(302)$ & $0.85(344)$ & $0.23(-0.04$ to 0.50$)$ \\
\hline \multicolumn{4}{|l|}{ Treatment at 6 weeks: } \\
\hline Satisfied or very satisfied & $81(253 / 311)$ & $91(329 / 361)$ & $9 \cdot 7(4.5 \text { to } 14 \cdot 9)^{\star \star}$ \\
\hline Partially or complete relieved & $77(245 / 317)$ & $87(312 / 360)$ & $9 \cdot 4(3.6 \text { to } 15 \cdot 2)^{\star \star}$ \\
\hline Any further treatment between 1 and 2 years & $41(38 / 92)$ & $36(39 / 107)$ & $-4.9(-18.5$ to $8 \cdot 7)$ \\
\hline \multicolumn{4}{|l|}{ Using drugsł: } \\
\hline At 6 months & $35(99 / 285)$ & $33(109 / 331)$ & $-1 \cdot 8(-9 \cdot 3$ to $5 \cdot 7)$ \\
\hline At 1 year & $29(62 / 212)$ & $30(75 / 251)$ & $0.7(-7.6$ to $9 \cdot 0)$ \\
\hline At 2 years & $36(33 / 92)$ & $30(32 / 107)$ & $-6 \cdot 0(-19 \cdot 1$ to $7 \cdot 1)$ \\
\hline \multicolumn{4}{|l|}{ Pain at 1 year: } \\
\hline Pain free for "several months" & $59(81 / 137)$ & $64(112 / 176)$ & $4.5(-6.4$ to 15.4$)$ \\
\hline Further equally severe episode & $25(33 / 131)$ & $24(42 / 172)$ & $-0.8(-10.6$ to 9.0$)$ \\
\hline Experiencing pain daily & $37(73 / 198)$ & $31(71 / 232)$ & $-6 \cdot 3(-15 \cdot 3$ to $2 \cdot 7)$ \\
\hline \multicolumn{4}{|c|}{ Oswestry score as high as or higher than before treatment: } \\
\hline At 6 months & $26(72 / 274)$ & $17(53 / 321)$ & $-9 \cdot 8(-16.4 \text { to }-3 \cdot 2)^{\star \star}$ \\
\hline Up to 1 year & $34(67 / 195)$ & $24(57 / 238)$ & $-10 \cdot 5(-19 \cdot 1 \text { to }-1 \cdot 9)^{\star}$ \\
\hline Up to 2 years & $45(37 / 83)$ & $28(27 / 97)$ & $-16 \cdot 8(-30 \cdot 7 \text { to }-2 \cdot 9)^{\star}$ \\
\hline
\end{tabular}

${ }^{\star} \mathrm{p}<0.05,{ }^{\star \star} \mathrm{p}<0.005$.

†Including treatment in general practice.

$\ddagger$ Mainly analgesics and anti-inflammatory drugs. practic lasted longer than that for those allocated to hospital effects on time off work during the first year were difficult to assess. Between one and two years the frequency and duration of absence from work were less in those treated by chiropractic. Of those with jobs, $21 \%(18 / 84)$ of patients given chiropractic had time off work because of back pain compared with $35 \%$ (26/74) of hospital patients $(\mathrm{p}=0.055)$.

\section{ECONOMIC IMPLICATIONS}

The potential economic, resource, and policy implications of our results are extensive. The average cost of chiropractic investigation and treatment at 1988-9 prices was $£ 165$ per patient compared with $£ 111$ for hospital treatment. Some 300000 patients are referred to hospital for back pain each year, " of whom about 72000 would be expected to have no contraindications to manipulation. ${ }^{12}$ If all these patients were referred for chiropractic instead of hospital treatment the annual cost would be about $£ 4 \mathrm{~m}$. Our results suggest that there might be a reduction of some 290000 days in sickness absence during two years, saving about $£ 13 \mathrm{~m}$ in output and $£ 2.9 \mathrm{~m}$ in social security payments. As it was not clear, however, that the improvement in those treated by chiropractic was related to the number of treatments the cost of essential chiropractic treatment might be substantially less than $£ 4 \mathrm{~m}$. The possibility that patients treated in hospital would need more treatment during the second year than those treated by chiropractic (see above and table VI) also has to be borne in mind. There is, therefore, economic support for use of chiropractic in low back pain, though the obvious clinical improvement in pain and disability attributable to chiropractic treatment is in itself an adequate reason for considering the use of chiropractic. treatment, and in eight chiropractic was more effective. No clear relation was found between the number of treatments and extent of improvement for either chiropractic or hospital treatment.

Table VI shows that the change in straight leg raising and lumbar flexion was greater in those treated by chiropractic than those treated in hospital and that for nearly all other subsidiary measures patients treated by chiropractors did better than those treated in hospital. The smaller proportions of patients treated in hospital than by chiropractic who were satisfied with their treatment or relieved by it may well account for the somewhat greater loss to follow up in the hospital group. Because treatment for those allocated to chiro-

\section{Discussion}

Though many randomised controlled trials of treatments for back pain have been carried out, there have so far been no clear indications in favour of any particular method. The place of manipulation in back pain has been reviewed by Jayson, ${ }^{13}$ who concluded that any minor benefits seemed to be confined to those with acute pain of recent onset, that there was no evidence that manipulation helped those with severe or chronic back problems, and that it did not reduce long 
term complications or prevent recurrences. For chiropractic our findings suggest otherwise. The difficulties of clinical trials in low back pain have been discussed. ${ }^{14}$ Our trial had the combined advantages of considerably larger numbers and a longer follow up period than other trials comparing orthodox treatments or, less often, orthodox and alternative treatments.

We studied only patients who had no contraindications to manipulation. Although this group represents a substantial proportion of all patients with back pain, the findings cannot be automatically applied to all patients with back pain. With this proviso the results leave little doubt that chiropractic is more effective than conventional hospital outpatient treatment. The confidence intervals for the differences in Oswestry scores were wide, but the degree of improvement recorded for many of the secondary outcome measures (table VI) suggests that chiropractic has appreciable benefit. The effects of chiropractic seem to be long term, as there was no consistent evidence of a return to pretreatment Oswestry scores during the two years of follow up, whereas those treated in hospital may have begun to deteriorate after six months or a year. Chiropractic was particularly effective in those with fairly intractable pain - that is, those with a history and severe pain. Although we have discussed the results in terms of differences at the various follow up intervals, the full effects of treatment are better thought of as an integrated benefit throughout the two year follow up period, represented by the area between the curves for the two treatments. The greater proportions of patients treated by chiropractic who were satisfied and relieved at six weeks, when $90 \%$ of patients had provided follow up data, strengthens the likelihood that the differences in Oswestry scores and other variables later on, when fewer patients have provided data, were true differences.

The results from the secondary outcome measures (table VI) suggest that the advantage of chiropractic starts soon after treatment begins. The reason for the much larger advantage later on is not obvious. Part of the explanation could be that hospital treatment is effective in the short term but not the longer term, perhaps because it is not given for as long as chiropractic. The undoubted difficulties under which some of the participating physiotherapy departments were working during the trial almost certainly meant that they were unable to give all the specific treatment they would have wished to all patients.

A central question is the extent to which the results could be due to biases and placebo effects. Patients were deliberately sent follow up Oswestry questionnaires at home to minimise any chance that their answers might be affected by actual or perceived influence by their therapist. Ideally, straight leg raising and lumbar flexion should have been measured by an assessor who was blind to the treatment allocation. The nurse coordinators, however, did not have the initial results available at the time of the follow up measurements at six weeks. In addition nearly all the other subsidiary measures suggested greater improvement among those treated by chiropractic.

The consequences of biased outcome measures or of a placebo effect associated with chiropractic would almost certainly have been more evident when treatment was still in progress or just afterwards. In fact, the main difference between hospital and chiropractic treatment was seen from six months or a year onwards, well after treatment and contact with therapists had ended.

The fact that chiropractic treatment tended to be more effective in those initially presenting to the chiropractors than in those presenting to hospital raises the possibility that the self assessment by the patients who presented to chiropractors may have been influenced by their expectation that chiropractic would be effective. The results in all patients who had been followed up for two years, however, indicate a similar effect of chiropractic in both referral groups (table V). There were several differences between the two referral groups that may have influenced response to treatment (these will be reported in detail elsewhere). For example, a significantly higher proportion of patients initially attending the chiropractors had had previous episodes of back pain. Those initially attending chiropractors had also waited much less time for appointments for the current episode and scored significantly less on questionnaires for depressive and inappropriate symptoms and for somatic awareness than the patients initially attending hospital. In addition, the analyses among the (non-clinic) subgroups prespecified in the minimisation procedure were balanced for referral clinic, there being similar proportions initially presenting to chiropractors and to hospital in each of the randomised treatment groups. Yet the tendency for chiropractic to be more effective was not universalfor example, the absence of clear benefit in those with no previous history of back pain. Finally, the self exclusion of many patients who initially presented to the chiropractors probably resulted in only a few of these patients who might automatically have assessed themselves as better after chiropractic or worse after hospital treatment being included. In summary, it is unlikely that the benefits of chiropractic are the result of biased outcome assessments or of a placebo effect.

Centres where chiropractic was more effective at six weeks and six months and those where there was less difference between the two treatments at that stage contributed to the results to about the same extent at a year and two years. The sustained effect of chiropractic was therefore probably not due to a disproportionate contribution from individual centres where there was an obvious early benefit from chiropractic.

In the absence of any clear relation between the number of treatment sessions and outcome, specific components of chiropractic responsible for its effectiveness have to be considered. An obvious possibility is the use of high velocity, low amplitude manipulation in virtually all the patients treated by chiropractic. Another is that chiropractic was given for a longer period than hospital treatment. Whatever the explanation for the difference between the two approaches, however, this pragmatic comparison of two types of treatment used in day to day practice shows that patients treated by chiropractors were not only no worse off than those treated in hospital but almost certainly fared considerably better and that they maintained their improvement for at least two years.

If our results are more widely applicable the practical implications are far reaching. Consideration should be given to recognising appropriately trained and experienced chiropractors and to providing chiropractic within the NHS, either in hospitals or by purchasing chiropractic treatment in existing clinics. Further trials to identify the specific component(s) responsible for the effectiveness of chiropractic should be undertaken. Whether the results of this trial can also be applied to other heterodox regimens of manipulation is an open question.

We thank the nurse coordinators, medical staff, physiotherapists, and chiropractors in the 11 centres for their work and Mr Alan Breen of the British Chiropractic Association for his help. The centres were in Harrow, Taunton, Plymouth, Bournemouth and Poole, Oswestry, Chertsey, Liverpool, Chelmsford, Birmingham, Exeter, and Leeds. Without the assistance of many staff members in each the trial could not have been completed. The study was supported by the Medical Research Council, the National Back Pain Association, the European Chiropractors Union, and the King Edward's Hospital Fund for London. 
ADDENDUM - In view of the long term benefit apparently due to chiropractic we initiated a three year follow up, sending multiple reminders to those initially not responding. By mid April 1990-beyond the closing date for the earlier results - data were available for 113 patients, representing a $79 \%$ response. At three years the mean fall in Oswestry score for those treated by chiropractic was $9.6 \%$ points more than for those treated in hospital $(p=0 \cdot 01)$. The fall was greater $(13.8 \% \mathrm{p}=0.003)$ among those presenting with current episodes of more than a month's duration than for those presenting with episodes of less than a month $(5 \cdot 3 \%$, NS). Among those with a previous history of back pain, the improvement in Oswestry score at three years was $9 \cdot 7 \%$ points greater in patients treated by chiropractic than those treated in hospital $(p=0 \cdot 02)$. A similar difference between the two forms of treatment $(9 \cdot 4 \%)$ was found among those with no previous history of back pain, but numbers in this group were smaller and the difference was not significant.
I British Medical Association. Alternative therapy. Report of the board of science and education. Spalding: Chameleon Press, 1986:77.

2 Department of Health and Social Security Working Group on Back Pain. Report to secretary of state for social services. London: HMSO, 1979.

Smith R. Trouble ahead for clinical trials. Br Med f 1988;297:1567.

4 Frank AO, Hills JE. Spinal pain. In: Frank AO, Maguire GP, eds. Disabling diseases: physical, environmental and psychosocial management. Oxford: Heinemann Medical Books, 1988:41-73.

5 Meade TW, Browne W, Mellows S, et al. Comparison of chiropractic and hospital outpatient management of low back pain: a feasibility study. f Epidemiol Community Health 1986;40:12-7.

6 Fairbank J, Davies J, Coupar J, O'Brien JP. The Oswestry low back pain disability questionnaire. Physiotherapy 1980;66:271-3.

7 Zinovieff A, Harborow PRH. Inclinometer for measuring straight-leg raising. Rheumatology and Rehabilitation, 1975;14:115.

$8 \mathrm{McCray}$ IF, Wright V. Measurement of back movement. Annals of Rheumatic Diseases 1969;28:584.

9 Main CJ, Waddell G. The detection of psychological abnormality in chronic low back pain using four simple scales. Current Concepts in Pain 1984;2:10-5.

10 Simon R. Sequential treatment assignment with balancing for prognostic factors in the controlled clinical trial. Biometrics 1975;31:103-15.

11 Glass JB. Acute lumbar strain: clinical signs and prognosis. Practitioner 1979;222:821-5.

12 Wood PHN, Badley EM. Epidemiology of back pain. In: Jayson MIV, ed. The lumbar spine and back pain. 2nd ed. Tunbridge Wells: Pitman Medical, 1980. 13 Jayson MIV. A limited role for manipulation. BrMed $\mathcal{F} 1986 ; 293: 1454-5$.

14 Grahame R. Clinical trials in low back pain. Clinics in Rheumatic Diseases 1980;6:143-57.

(Accepted 30 March 1990)

\section{Low molecular weight heparins and hypoaldosteronism}

H Levesque, S Verdier, N Cailleux, M C ElieLegrand, A Gancel, J P Basuyau, J Y Borg, N Moore, $\mathrm{H}$ Courtois

\section{Centre Hospitalier}

Universitaire de Rouen-

Boisguillaume, BP 100,

76233 Boisguillaume,

France

$\mathrm{H}$ Levesque, MD, consultant in internal medicine

$\mathrm{S}$ Verdier, house officer

$\mathrm{N}$ Cailleux, house officer

M C Elie-Legrand, MD,

registrar

A Gancel, MD, consultant

J Y Borg, MD, consultant in

haemotology

$\mathrm{N}$ Moore, $\mathrm{MD}$, associate professor of pharmacology $\mathrm{H}$ Courtois, MD, professor of internal medicine

\section{Laboratoire}

d'Hormonologie, Centre

Henri Bequerel, 76000

Rouen, France

J P Basuyau, MD, consultant

in radioimmunology

Correspondence to: $\mathrm{Dr}$ Levesque.

Br Med f 1990;300:1437-8
Treatment with heparin can impair production of aldosterone, ${ }^{12}$ though this is usually not clinically important. We diagnosed hyperkalaemia related to hypoaldosteronism in a 79 year old woman who was being treated with low molecular weight heparin; the condition resolved when the treatment was withdrawn. This prompted a prospective, randomised systematic study of the effects of the low molecular weight heparins on adrenal function.

\section{Patients, methods, and results}

Twenty seven patients in hospital who were confined to bed were given low molecular weight heparin, either Fraxiparine (3300 anti-factor $\mathrm{X}$ a units daily) or enoxaparin ( 2100 units daily), to prevent thromboembolic complications. The treatment was stopped when the patients could get up. The doses were available prepackaged in subcutaneous injection syringes and designed to prevent venous thrombosis Patients who had diabetes mellitus or renal insufficiency, or were taking drugs known to interfere with aldosterone metabolism (converting enzyme inhibitors or antialdosterone drugs) were not included. Two patients continued taking frusemide $(20 \mathrm{mg} /$ day $)$ during the study; none of the other patients took diuretics. All patients received the standard hospital diet (normal salt intake) throughout the study.

Blood samples were taken before treatment, after four days of treatment, and three days after treatment had been stopped. Blood was taken in the morning after at least 12 hours' supine rest. It was analysed for serum sodium and potassium concentrations with an automatic analyser (Technicon, Dublin, Ireland), and plasma aldosterone and cortisol concentrations and renin activity with a radioimmunoassay. (The plasma samples were kept at $-20^{\circ} \mathrm{C}$ until the end of the analysis, and each patient's plasma was assayed for all three periods simultaneously to eliminate interassay variations.)

\section{Results}

Twelve patients received enoxaparin (seven women, five men; mean (SD) age $68.3(11 \cdot 7)$ years (range 37$79)$ ), and 15 received Fraxiparine (11 women, four men; mean age $70.3(13.0)$ years (range $34-85)$ ). The plasma aldosterone concentration had decreased after four days of treatment by a mean of $43.9(4 \cdot 11) \%$ $(p<0.001)$. Three days after the treatment was stopped the concentration had almost returned to initial values (table). No difference was found between patients receiving enoxaparin and Fraxiparine. The two patients taking frusemide, who initially had high plasma aldosterone concentrations also had decreased plasma aldosterone concentrations during treatment with low molecular weight heparin. In four patients (three taking enoxaparin, one Fraxiparine) plasma aldosterone was not detectable during treatment.

The mean serum potassium concentration increased significantly $(p<0.001)$ during treatment with both drugs and decreased after treatment was stopped. The other variables measured did not change significantly.

\section{Comment}

We found that low molecular weight heparin inhibited the production of aldosterone, as does standard heparin. The mechanism whereby heparin inhibits aldosterone biosynthesis is not proved. Several

Mean (SD) values of biochemical variables measured in elderly patients before, during (after four days' treatment), and (three days) after treatment with low molecular weight heparins

\begin{tabular}{|c|c|c|c|c|c|c|}
\hline & \multicolumn{3}{|c|}{ Fraxiparine } & \multicolumn{3}{|c|}{ Enoxaparin } \\
\hline & Before & During & After & Before & During & After \\
\hline Plasma aldosterone ( $\mathrm{pmol} / \mathrm{l})$ & $332 \cdot 6(204 \cdot 6)$ & $184 \cdot 7(109 \cdot 2)^{\star \star}$ & $266 \cdot 6(150 \cdot 4)^{\star} \dagger$ & $285 \cdot 4(105 \cdot 8)$ & $174 \cdot 2(113 \cdot 7)^{\star \star}$ & $220 \cdot 4(97 \cdot 8)^{\star} \dagger$ \\
\hline Plasma renin activity $(\mathrm{nmol} / / \mathrm{h})$ & $33 \cdot 4(24 \cdot 6)$ & $31.4(14.9)$ & $30 \cdot 3(26 \cdot 0)$ & $23 \cdot 1(14 \cdot 2)$ & $25 \cdot 5(10 \cdot 0)$ & $22 \cdot 2(7 \cdot 7)$ \\
\hline Cortisol $(\mathrm{nmol} / \mathrm{l})$ & $511 \cdot 1(114 \cdot 3)$ & $516 \cdot 1(156 \cdot 2)$ & $496 \cdot 8(149 \cdot 1)$ & $527 \cdot 3(101 \cdot 9)$ & $489 \cdot 4(150 \cdot 2)$ & $664 \cdot 5(133)$ \\
\hline Serum sodium $(\mathrm{mmol} / \mathrm{l})$ & $141(2 \cdot 5)$ & $139 \cdot 7(2 \cdot 2)$ & $139 \cdot 6(1 \cdot 8)$ & $139 \cdot 6(2 \cdot 6)$ & $138 \cdot 6(3 \cdot 4)$ & $138 \cdot 5(2 \cdot 9)$ \\
\hline Serum potassium $(\mathrm{mmol} / \mathrm{l})$ & $4 \cdot 0(0 \cdot 3)$ & $4.4(0.4)^{\star \star}$ & $4 \cdot 2(0 \cdot 4)$ & $4 \cdot 1(0.3)$ & $4.5(0.4)^{\star \star}$ & $4.3(0.4)$ \\
\hline
\end{tabular}

${ }^{\star} \mathrm{p}<0.05,{ }^{\star \star} \mathrm{p}<0.001$ Compared with value before treatment by paired $t$ test.

$t \mathrm{p}<0.05$ Compared with value during treatment by paired $t$ test 